\title{
Optimization of Growth Environment in a Plant Production Facility Using a Chlorophyll Fluorescence Method
}

\author{
Kee-Sung KIM ${ }^{1}$, Gene A. GIACOMELII ${ }^{1}$, Sadanori SASE ${ }^{2 *}$, Jung-Eek SON ${ }^{3}$, \\ Sang-Woon NAM ${ }^{4}$ and Fumio NAKAZAWA ${ }^{5}$ \\ ${ }^{1}$ Department of Agricultural \& Biosystem Engineering, University of Arizona \\ (Tucson, AZ 85705, USA) \\ 2 Department of Agricultural Environment Engineering, National Institute for Rural Engineering \\ (Tsukuba, Ibaraki 305-8609, Japan) \\ ${ }^{3}$ School of Plant Science, Seoul National University (Seoul 151-742, Korea) \\ ${ }^{4}$ Department of Rural Infrastructure Engineering, Chungnam National University \\ (Deajeon 305-764, Korea) \\ ${ }^{5}$ School of Agriculture, Meiji University (Kawasaki, Kanagawa 214-8571, Japan)
}

\begin{abstract}
Chlorophyll fluorescence has been known as one of the indicators of photosynthetic status to various environmental stresses. The aims of this study were to assess the effects of environmental factors on lettuce chlorophyll fluorescent responses $(\mathrm{Fv} / \mathrm{Fm})$ and to develop an environment optimization model for lettuce growth using a simple genetic algorithm. High values of $\mathrm{Fv} / \mathrm{Fm}$ were observed when environmental factors were $22-26^{\circ} \mathrm{C}$ ambient temperature, $15-23^{\circ} \mathrm{C}$ root zone temperature, $900-1,600 \mathrm{ppm}$ $\mathrm{CO}_{2}$ concentration, $0.4-1.3 \mathrm{~m} \cdot \mathrm{s}^{-1}$ air current speed, and $65-85 \%$ relative humidity. As photosynthesis photon flux (PPF) increased over $150 \mu \mathrm{mol} \cdot \mathrm{m}^{-2} \cdot \mathrm{s}^{-1}, \mathrm{Fv} / \mathrm{Fm}$ values were decreased. Principle component analysis was used to estimate the combined effects of six environmental factors on lettuce growth. The developed model fitted observed Fv/Fm values with an average standard error of $1.2 \%$. An optimal environment for lettuce growth was estimated by the model to be $22^{\circ} \mathrm{C}$ ambient temperature, $20^{\circ} \mathrm{C}$ root zone temperature, $1,578 \mathrm{ppm} \mathrm{CO}_{2}$ concentration, $1.3 \mathrm{~m} \cdot \mathrm{s}^{-1}$ air current speed, $216 \mu \mathrm{mol} \cdot \mathrm{m}^{-2} \cdot \mathrm{s}^{-1}$ $\mathrm{PPF}$, and $75 \%$ relative humidity. The Fv/Fm value can be a good indicator of plant stress level and thus a useful parameter to optimize the environment for plant growth.
\end{abstract}

Discipline: Agricultural facilities

Additional key words: environmental stress, Fv/Fm, genetic algorithm, JAVA, principle component analysis

\section{Introduction}

Plant bio-information has been used to develop plant physiological models to optimize cultivation environments in controlled plant production systems ${ }^{10,13}$. Shimizu and Yamazaki ${ }^{23}$ used morphological characteristics of leaves as parameters for a plant growth model. Dry and fresh weight, stem diameter, leaf area, and photosynthetic rate have been commonly used as indicators of plant growth. However, a precise measurement of photosynthesis requires expensive equipment and its responses to irregular plant physiological characteristics still need to be investigated ${ }^{29}$. These methods have disadvantages including damages to the plant, requirement of expensive equipment, and difficulties of measurements.

Chlorophyll fluorescence is one of the well-known indicators of photosynthetic stress status in various environments ${ }^{22}$. Chlorophyll fluorescence is often used to analyze spatial and visual photosynthesis without damage to the plant ${ }^{2}$. Fluorescence response can be a useful parameter for mathematical models for environment control $^{29}$. Lichtenthaler ${ }^{18}$ and Babani et al. ${ }^{1}$ have used Fv/ Fm ratio as an abiotic stress index.

Several studies used chlorophyll fluorescence responses to light stress ${ }^{3}$, heat and chilling stress ${ }^{20}$, and

This research was carried out under the US-Japan collaborative project on analysis and control of greenhouse environment for efficient crop production under semiarid climate.

*Corresponding author: fax +81-29-838-7609; e-mail sase@nkk.affrc.go.jp

Received 31 March 2005; accepted 25 July 2005. 
water stress ${ }^{21}$. Willits and Peet ${ }^{30}$ measured the chlorophyll fluorescence of tomato as a parameter of heat stress for a model. There have been a few studies on the chlorophyll fluorescence response method for plant growth environment. However, this method has not been applied to plant cultivation environment control.

The objectives of this study were to assess chlorophyll fluorescence $(\mathrm{Fv} / \mathrm{Fm})$ responses to microclimatic changes of ambient temperature, photosynthesis photon flux (PPF), relative humidity, $\mathrm{CO}_{2}$ concentration, air current speed, and root zone temperature. The measured Fv/ Fm values were regressed against each environmental factor. Using the regression equations and a simple genetic algorithm, an optimal environment for lettuce growth was predicted.

\section{Materials and methods}

\section{Measurements of chlorophyll fluorescence and environmental variables}

Chlorophyll fluorescence is the emitted light that is not used for the photosynthetic process. Therefore, the fluorescence change is a useful index to reflect the photosynthetic efficiency ${ }^{5}$. When exposed to a weak light after a few minutes residence in a dark place, a plant leaf emits an amount of Fo, dark or initial fluorescence. In this case, the light absorbed by chlorophyll is not available for photosynthesis and is emitted as fluorescence. The Fm value, maximum fluorescence, is the fluorescence emission when a dark-adapted leaf is exposed to saturated light. In general, the Fo value increases as plant stress increases, while the Fm value decreases. The ratio of Fo to Fm is commonly used to remove the dependence on the amount of chlorophyll, thickness, and age of the leaf since Fo and Fm values vary with these factors ${ }^{16}$. Maximum variable fluorescence, Fv, is the difference between Fm and Fo. The ratio, Fv/Fm, indicates a maximum potential of plant photosynthetic ability. Healthy plant leaves generally show an Fv/Fm value of 0.83 and a ratio below 0.83 means that plants are under stress ${ }^{11,17}$.

Measurements of chlorophyll fluorescence started at day 11 after transplantation using a fluorometer (MINIPAM, Walz, Germany) with the standard setting ${ }^{26}$. One environmental factor was controlled at a time in order to assess the individual effect on Fv/Fm. Table 1 shows the ranges of the environmental factors controlled.

Lettuce was acclimated for an hour every time a treatment changed. An additional 5 min was applied for the dark adaptation before the measurements of fluorescence response ${ }^{25}$. Four leaves of each lettuce head were chosen to measure fluorescence responses. The fluorescence response was measured twice for each leaf. After-
Table 1. Ranges of environmental variables

\begin{tabular}{lc}
\hline \hline Environmental factor & Range \\
\hline Ambient temperature $\left({ }^{\circ} \mathrm{C}\right)$ & $10-36$ \\
Root zone temperature $\left({ }^{\circ} \mathrm{C}\right)$ & $5-35$ \\
$\mathrm{CO}_{2}(\mathrm{ppm})$ & $400-2,000$ \\
Air current speed $\left(\mathrm{m} \cdot \mathrm{s}^{-1}\right)$ & $0.1-2.5$ \\
PPF $\left(\mu \mathrm{mol} \cdot \mathrm{m}^{-2} \cdot \mathrm{s}^{-1}\right)$ & $30-400$ \\
Relative humidity $(\%)$ & $50-95$ \\
\hline
\end{tabular}

ward, the initial environment conditions were applied for $24 \mathrm{~h}$ in order for lettuce to recover from previous stress. Once lettuce fully recovered, another treatment was applied. This procedure was repeated for $30 \mathrm{~d}$ after transplantation. After a series of measurements for each environmental treatment, a new set of lettuce was prepared for the next environmental treatment. In total, 6 sets of lettuce were used for this study.

Leaf lettuce (Lactuca sativa L.) was grown in a growth chamber. Environmental factors of air temperature (T-type thermocouple, Omega, USA), PPF (PP-1, PP-system, UK), relative humidity (Hobo, Onset Computer, USA), $\mathrm{CO}_{2}$ concentration (GMW-22, Vaisala, Finland), air current speed (Series 640, Dwyer, USA) and root zone temperature (T-type thermocouple, Omega, USA) were measured every $5 \mathrm{~min}$ and stored in a datalogger (DC100, Yokogawa, Japan). Fluorescent lamps (12 ea.), high-pressure sodium lamps (4 ea.), and highpressure mercury vapor lamps (4 ea.) were used as light sources for the plant growth. Nutrient film $(110(\mathrm{~W}) \times 50$ $(\mathrm{L}) \times 13(\mathrm{D}) \mathrm{cm})$ served as a platform for lettuce growth. Yamazaki solution (pH: $6.5 \pm 0.5$, EC: $1.2 \pm 0.05 \mathrm{mS}$. $\mathrm{cm}^{-1}$ ) supplied nutrients and was remade every $8 \mathrm{~h}^{14}$. After the transplantation of 10 lettuce heads, the environmental conditions were maintained for 10 days at $400 \pm$ $30 \mu \mathrm{mol} \cdot \mathrm{m}^{-2} \cdot \mathrm{s}^{-1}$ PPF (12-h photoperiod), $22 \pm 2^{\circ} \mathrm{C}$ air temperature, $65 \pm 5 \%$ relative humidity, $300 \pm 50 \mathrm{ppm}$ $\mathrm{CO}_{2}$ concentration, $0.1 \pm 0.03 \mathrm{~m} \cdot \mathrm{s}^{-1}$ air current speed, and $20 \pm 2^{\circ} \mathrm{C}$ root zone temperature ${ }^{19}$. Chlorophyll fluorescence was measured after 2-h exposure to artificial light. For 11 days, the measured $\mathrm{Fv} / \mathrm{Fm}$ ratio was maintained at $0.821 \pm 0.005$.

\section{Statistical analysis and genetic algorithm}

Chlorophyll fluorescence responses were regressed over each of the six environmental factors. Principle component analysis ${ }^{12}$ was applied to evaluate correlations among the six environmental factors. Principal components were derived by the linear combination of variables as independent variables accounting for correlations among variables. A chlorophyll fluorescence response 
model was developed in the form of a multi-variable function using the principal components.

A simple genetic algorithm was applied to find an optimal solution of the multi-variable function. Genetic algorithms are trial and error methods to optimize issues with complex objective functions employing the concepts of crossover and mutation from genetics and evolution ${ }^{9}$. A simple genetic algorithm has been applied to a number of optimization problems because of its powerfulness in finding a solution ${ }^{6}$.

In an evolution process, individuals with better fitness to the environment have higher possibilities to survive. Two processes, crossover and mutation, come into play a role in reproducing the next generation. A population, a set of individuals, has to be sized first in order to apply a genetic algorithm to a chlorophyll fluorescence model. Each individual consists of a chromosome, which is a group of multiple genes. In this study, chromosomes consisting of six environmental factors made up of a population, which is the chlorophyll fluorescence response model. The number of chromosomes was assigned by 10 genes to find fast a dominant gene. The chromosome size of each environmental factor is presented in Table 2.

A random initialization technique generated an initial population in the combination of the six environmental factors. The chlorophyll fluorescence response model served as an objective function to test the fitness of each gene. The objective function governed the population evolution through the processes of reproduction, crossover and mutation. At the end of each evolution period, fitness of the generation was tested in comparison with boundary conditions given in Table 3 . An initial population with 50 chromosomes was allowed to evolve for 20 generations to find an optimal solution. Fig. 1 presents the overall schematic diagram for the development of a cultivation environment optimization model.

The computational process for optimization was coded in Java language (Java 2 standard development kit V 1.3.2, SUN, USA). The SAS software package (Version 8, SAS Institute, USA) was used for the statistical analyses of experimental data.

\section{Results and discussion}

\section{Chlorophyll fluorescence response to environmental factors}

Correlation among the environmental factors was analyzed using the $\mathrm{Fv} / \mathrm{Fm}$ measurements at initial growth conditions $\left(22 \pm 2^{\circ} \mathrm{C}\right.$ ambient temperature, $20 \pm 2{ }^{\circ} \mathrm{C}$ root zone temperature, $65 \pm 5 \%$ relative humidity, $300 \pm 50$ ppm $\mathrm{CO}_{2}$ concentration, $0.1 \pm 0.05 \mathrm{~m} \cdot \mathrm{s}^{-1}$ air current speed, and $\left.400 \pm 30 \mu \mathrm{mol} \cdot \mathrm{m}^{-2} \cdot \mathrm{s}^{-1} \mathrm{PPF}\right)$. As shown in Table 4, low correlation coefficients indicate that environmental factors can be independent of one another.

In the ambient temperature treatment experiment, chlorophyll fluorescence was measured at every $2^{\circ} \mathrm{C}$ interval as the temperature increased from $20^{\circ} \mathrm{C}$ to $36^{\circ} \mathrm{C}$ and decreased from $20^{\circ} \mathrm{C}$ to $10^{\circ} \mathrm{C}$. The $\mathrm{Fv} / \mathrm{Fm}$ value was $0.819 \pm 0.005$ in range between 22 and $26^{\circ} \mathrm{C}$ ambient temperature, whereas it decreased at below $22^{\circ} \mathrm{C}$ or above

Table 2. Chromosome size and number

\begin{tabular}{lcrcrcc}
\hline \hline Factor & Data degree & Start point & End point & Range & $\begin{array}{c}\text { Size of } \\
\text { chromosome }\end{array}$ & $\begin{array}{c}\text { Fixed data } \\
\text { range* }\end{array}$ \\
\hline $\mathrm{AT}$ & 1 & 0 & 40 & 40 & 63 & 0.635 \\
$\mathrm{RZT}$ & 1 & 0 & 40 & 40 & 63 & 0.635 \\
$\mathrm{RH}$ & 5 & 25 & 100 & 75 & 15 & 5 \\
$\mathrm{ACS}$ & 0.1 & 0 & 2.0 & 2 & 31 & 0.0645 \\
$\mathrm{CO}_{2}$ & 15 & 300 & 2,000 & 1,700 & 127 & 13.386 \\
$\mathrm{PPF}$ & 15 & 0 & 700 & 700 & 63 & 11.111 \\
\hline
\end{tabular}

*: Range/Size of chromosome.

$\mathrm{AT}$ : Ambient temperature, RZT : Root zone temperature, $\mathrm{CO}_{2}: \mathrm{CO}_{2}$ concentration.

ACS: Air current speed, PPF : Photosynthetic photon flux, RH : Relative humidity.

Table 3. Boundary conditions for optimizing environmental conditions

\begin{tabular}{ccccccc}
\hline \hline Factor & $\begin{array}{c}\mathrm{AT} \\
\left({ }^{\circ} \mathrm{C}\right)\end{array}$ & $\begin{array}{c}\mathrm{RZT} \\
\left({ }^{\circ} \mathrm{C}\right)\end{array}$ & $\begin{array}{c}\mathrm{CO}_{2} \\
(\mathrm{ppm})\end{array}$ & $\begin{array}{c}\mathrm{ACS} \\
\left(\mathrm{m} \cdot \mathrm{s}^{-1}\right)\end{array}$ & $\begin{array}{c}\mathrm{PPF} \\
\left(\mu \mathrm{mol} \cdot \mathrm{m}^{-2} \cdot \mathrm{s}^{-1}\right)\end{array}$ & $\begin{array}{c}\mathrm{RH} \\
(\%)\end{array}$ \\
\hline Range & $22-26$ & $15-23$ & $350-1,650$ & $0.2-1.4$ & $100-500$ & $35-85$ \\
\hline
\end{tabular}


$26^{\circ} \mathrm{C}$ (Fig. 2). Eq. (1) presents the regression between the $\mathrm{Fv} / \mathrm{Fm}$ value and air temperature $\left(\mathrm{R}^{2}=0.92\right)$.

$$
\begin{aligned}
F v / F m_{A T}= & -0.000844185(A T)^{2}+0.0404832015(A T) \\
& +0.3251895488
\end{aligned}
$$

The highest Fv/Fm value was observed when the ambient temperature was $24^{\circ} \mathrm{C}$. The optimal ambient temperature for lettuce cultivation was reported to be 20

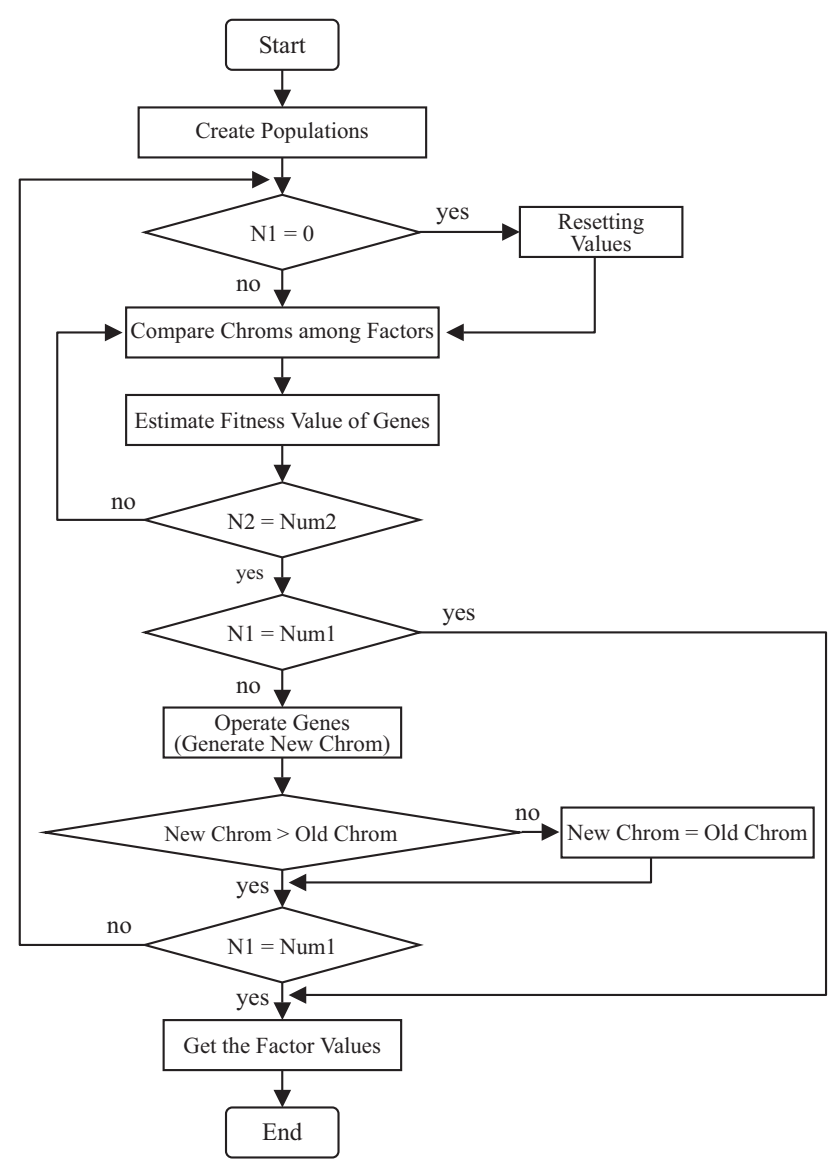

Fig. 1. Flowchart for optimization of plant environment control

N1: Current number of genes, N2: Current number of chromosomes, Num1: Number of chromosomes, Num2: number of genes. $\pm 2^{\circ} \mathrm{C}^{15}$, a temperature in which high $\mathrm{Fv} / \mathrm{Fm}$ values were observed. Wang ${ }^{27}$ reported that freezing stresses between 0 and $15^{\circ} \mathrm{C}$ could be either reversible or irreversible, although normal ambient temperatures were reapplied ${ }^{4}$.

Not only ultraviolet but visible light can cause plant stresses. The $\mathrm{Fv} / \mathrm{Fm}$ value decreased as PPF increased above $145 \mu \mathrm{mol} \cdot \mathrm{m}^{-2} \cdot \mathrm{s}^{-1}$, whereas the $\mathrm{Fv} / \mathrm{Fm}$ value was $0.810 \pm 0.002$ at PPF between 30 and $145 \mu \mathrm{mol} \cdot \mathrm{m}^{-2} \cdot \mathrm{s}^{-1}$ (Fig. 3). A regression between $\mathrm{Fv} / \mathrm{Fm}$ and PPF is given in Eq. (2) $\left(\mathrm{R}^{2}=0.87\right)$.

$F v / F m_{P P F}=-0.0000324364(P P F)+0.8097494887$

The Fv/Fm value was 0.795 at the light level of saturation $\left(\mathrm{PPF}=470 \mu \mathrm{mol} \cdot \mathrm{m}^{-2} \cdot \mathrm{s}^{-1}\right)$ of lettuce. Oxygen gen-

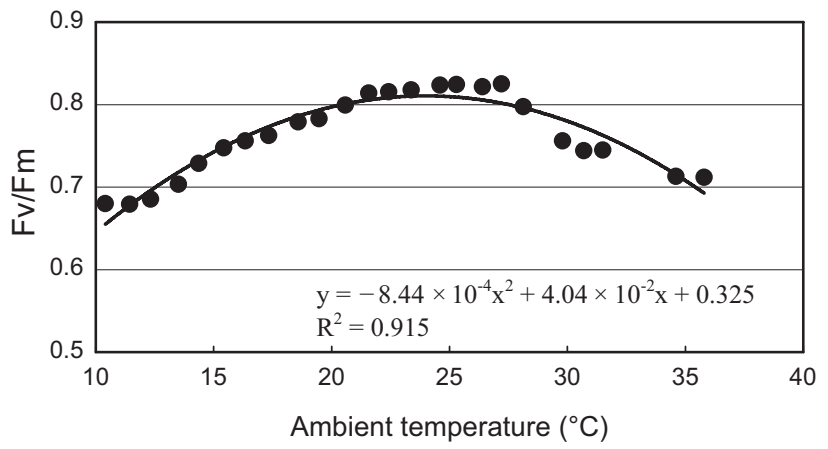

Fig. 2. Relationship between $\mathbf{F v} / \mathbf{F m}$ and ambient temperature

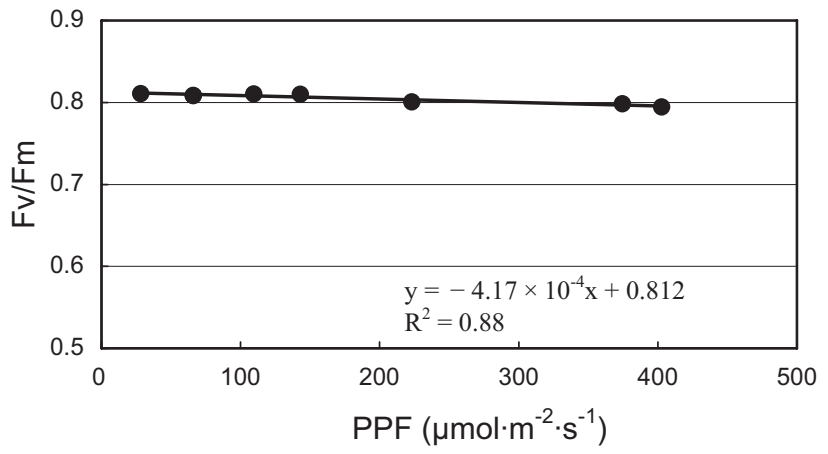

Fig. 3. Relationship between Fv/Fm and PPF

Table 4. Correlation coefficients among the environmental factors

\begin{tabular}{lrrrrrr}
\hline \hline Factor & \multicolumn{1}{c}{$\mathrm{AT}$} & \multicolumn{1}{c}{$\mathrm{RZT}$} & \multicolumn{1}{c}{$\mathrm{CO}_{2}$} & \multicolumn{1}{c}{$\mathrm{ACS}$} & \multicolumn{1}{c}{$\mathrm{PPF}$} & \multicolumn{1}{c}{$\mathrm{RH}$} \\
\hline $\mathrm{AT}$ & 1.00000 & -0.02696 & -0.03786 & 0.02959 & 0.03418 & 0.02262 \\
$\mathrm{RZT}$ & -0.02696 & 1.00000 & 0.02081 & 0.01896 & -0.00400 & 0.17001 \\
$\mathrm{CO}_{2}$ & -0.03786 & 0.02081 & 1.00000 & 0.17846 & -0.05732 & -0.02290 \\
$\mathrm{ACS}$ & 0.02959 & 0.01896 & 0.17846 & 1.00000 & -0.03939 & 0.05764 \\
$\mathrm{PPF}$ & 0.03418 & -0.00400 & -0.05732 & -0.03939 & 1.00000 & -0.04160 \\
$\mathrm{RH}$ & 0.02262 & 0.17001 & -0.02290 & 0.05764 & -0.04160 & 1.00000 \\
\hline
\end{tabular}


eration of lettuce was decreased by 35 to $40 \%$ after 2 -h exposure to visible light of $325 \mu \mathrm{mol} \cdot \mathrm{m}^{-2} \cdot \mathrm{s}^{-124}$. It seemed that light intensity as well as exposure time could cause plant stresses.

When $\mathrm{CO}_{2}$ concentrations were controlled between 900 and $1,600 \mathrm{ppm}$, the $\mathrm{Fv} / \mathrm{Fm}$ value was $0.813 \pm 0.002$. $\mathrm{CO}_{2}$ concentrations out of this range resulted in decreased $\mathrm{Fv} / \mathrm{Fm}$ values. Park and $\mathrm{Lee}^{19}$ reported the optimal condition for lettuce growth was 1,000-2,000 ppm $\mathrm{CO}_{2}$ concentration when PPF was greater than 200 $\mu \mathrm{mol} \cdot \mathrm{m}^{-2} \cdot \mathrm{s}^{-1}$. This study also indicated a decrease in the $\mathrm{Fv} / \mathrm{Fm}$ value when $\mathrm{CO}_{2}$ concentration was out of the range of $900-1,600 \mathrm{ppm}$ and suggested that the $\mathrm{Fv} / \mathrm{Fm}$ value can serve as an indicator for environment control. A regression model (Eq. (3), $\mathrm{R}^{2}=0.74$ ) between the $\mathrm{Fv} /$ Fm value and $\mathrm{CO}_{2}$ concentration predicted the highest $\mathrm{Fv} / \mathrm{Fm}$ value at 1,210 ppm $\mathrm{CO}_{2}$ concentration (Fig. 4).

$$
\begin{aligned}
\mathrm{Fv} / \mathrm{Fm}_{\mathrm{CO} 2}= & -0.0000000234\left(\mathrm{CO}_{2}\right)^{2}-0.0000567595\left(\mathrm{CO}_{2}\right) \\
& +0.7792088389
\end{aligned}
$$

The Fv/Fm value was $0.806 \pm 0.003$ at $65-85 \%$ relative humidity. It has been known that high or low relative humidity decreases the photosynthetic ability of plants? This is because photosynthesis is reduced in the range of $10-20 \%$ relative humidity due to stomata closure and the decrease in intercellular $\mathrm{CO}_{2}$ concentration levels. The maximum $\mathrm{Fv} / \mathrm{Fm}$ value was predicted to be at $75 \%$ relative humidity (Fig. 5). A regression model between Fv/ Fm and relative humidity is given in Eq. (4) $\left(\mathrm{R}^{2}=0.73\right)$. $\mathrm{Fv} / \mathrm{Fm}$ values decreased when relative humidity was below $60 \%$ or above $85 \%$, which suggests the $\mathrm{Fv} / \mathrm{Fm}$ value can be an indicator for humidity control.

$$
\begin{aligned}
F v / F m_{R H}= & -0.0000198754(R H)^{2}+0.00301791(R H) \\
& +0.6906904622
\end{aligned}
$$

The $\mathrm{Fv} / \mathrm{Fm}$ value was $0.810 \pm 0.003$ at air current speeds between 0.4 and $1.3 \mathrm{~m} \cdot \mathrm{s}^{-1}$, while it decreased above $1.3 \mathrm{~m} \cdot \mathrm{s}^{-1}$ (Fig. 6). A regression model showed the highest $\mathrm{Fv} / \mathrm{Fm}$ value at $0.9 \mathrm{~m} \cdot \mathrm{s}^{-1}$ air current speed (Eq. (5)).

$$
\begin{aligned}
F v / F m_{A C S}= & -0.013584327(A C S)^{2}+0.0227660957(A C S) \\
& +0.7968448588
\end{aligned}
$$

Kitaya et al. ${ }^{15}$ reported that the net photosynthetic rate and transpiration rate significantly increased as the air current speed increased from 0.01 to $0.2 \mathrm{~m} \cdot \mathrm{s}^{-1}$. The transpiration rate increased gradually with the increase of air current speeds from 0.2 to $1.0 \mathrm{~m} \cdot \mathrm{s}^{-1}$, whereas the net photosynthetic rate remained constant at $0.5-1.0 \mathrm{~m} \cdot \mathrm{s}^{-1}$.

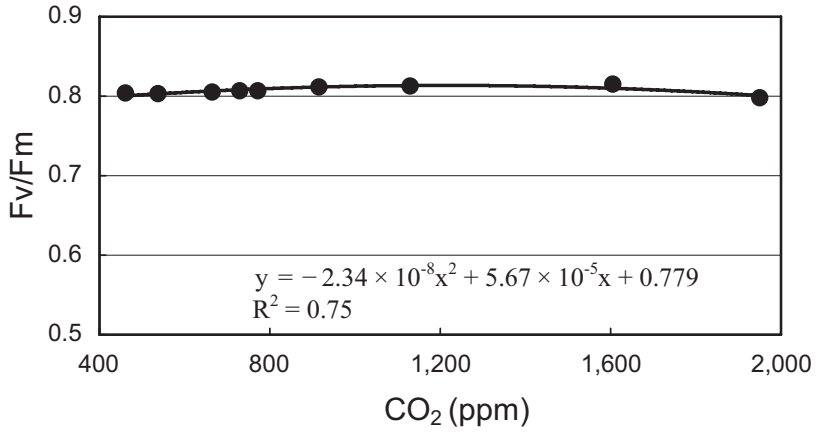

Fig. 4. Relationship between $\mathrm{Fv} / \mathrm{Fm}$ and $\mathrm{CO}_{2}$

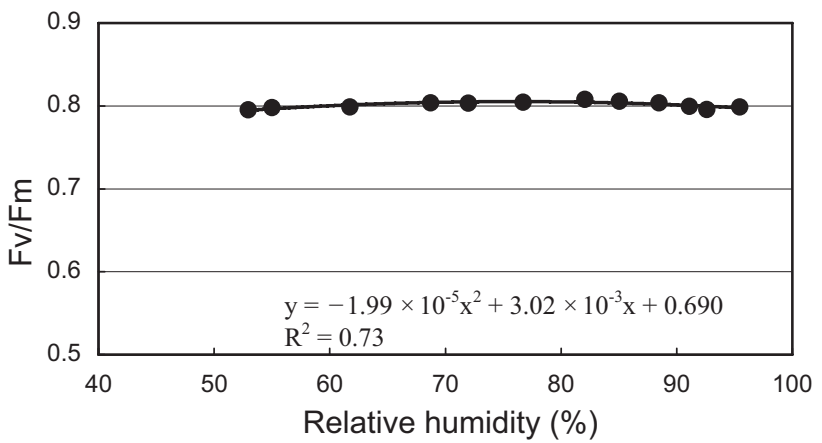

Fig. 5. Relationship between Fv/Fm and relative humidity

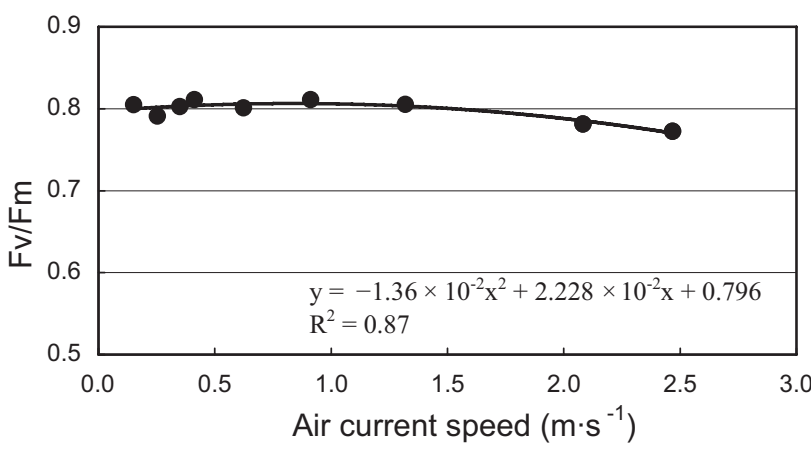

Fig. 6. Relationship between Fv/Fm and air current speed

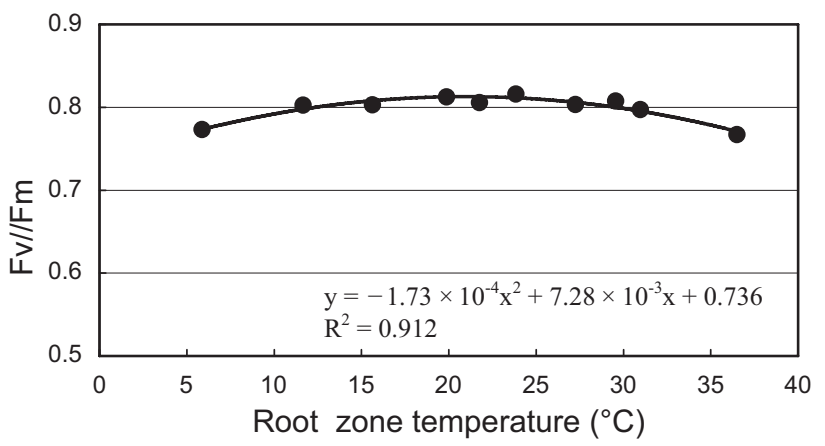

Fig. 7. Relationship between Fv/Fm and root zone temperature

The $\mathrm{Fv} / \mathrm{Fm}$ value was $0.809 \pm 0.005$ in the range of $12-23^{\circ} \mathrm{C}$ root zone temperature (RZT) (Fig. 7). A regression model between $\mathrm{Fv} / \mathrm{Fm}$ and RZT predicted an optimal RZT of $20^{\circ} \mathrm{C}$ for lettuce growth (Eq. (6), $\mathrm{R}^{2}=0.91$ ). 
Table 5. Eigenvectors of measured $\mathrm{Fv} / \mathrm{Fm}$ values

\begin{tabular}{llllrrr}
\hline \hline Factor & PRIN 1 & PRIN 2 & PRIN 3 & PRIN 4 & \multicolumn{1}{c}{ PRIN 5 } & \multicolumn{1}{c}{ PRIN 6 } \\
\hline $\mathrm{AT}$ & 0.310031 & 0.604803 & 0.154923 & -0.349728 & -0.615815 & -0.112049 \\
$\mathrm{RZT}$ & -0.010160 & 0.352778 & 0.792585 & 0.164640 & 0.461040 & -0.086576 \\
$\mathrm{CO}_{2}$ & 0.257798 & -0.157072 & 0.142569 & -0.589761 & 0.224641 & 0.696423 \\
$\mathrm{ACS}$ & 0.198054 & -0.86639 & -0.105189 & 0.396624 & 0.123957 & -0.047444 \\
$\mathrm{PPF}$ & -0.020619 & 0.614584 & -0.560323 & -0.138832 & 0.536436 & -0.029354 \\
$\mathrm{RH}$ & -0.168842 & 0.316022 & -0.49549 & 0.571123 & -0.233713 & 0.701307 \\
Eigenvalue & 2.36356441 & 1.38351051 & 1.12060559 & 0.74507042 & 0.27673273 & 0.11051635 \\
Proportion & 0.3939 & 0.2306 & 0.1868 & 0.1242 & 0.0461 & 0.0814 \\
\hline
\end{tabular}

$$
\begin{aligned}
F v / F m_{R Z T}= & -0.0001730903(R Z T)^{2}+0.0072890537(R Z T) \\
& +0.736501178
\end{aligned}
$$

RZT is one of the most important factors affecting plant rooting ${ }^{28}$. He et al. ${ }^{8}$ reported that the optimal range of RZT for lettuce growth was between 15 and $25^{\circ} \mathrm{C}$, and the photosynthesis increased by maintaining the RZT at $20^{\circ} \mathrm{C}$ when the ambient temperature was under $38^{\circ} \mathrm{C}$.

\section{Chlorophyll fluorescence response model using principle component analysis}

Principle component analysis was used to estimate the combined effects of the environmental factors on lettuce growth. Environment conditions were randomly set within the ranges of environmental boundaries as given in Table 3. As a result, each of the six environmental variables showed significance in explaining the observed values of $\mathrm{Fv} / \mathrm{Fm}(\mathrm{P}=0.0001)$.

As shown in Table 5, PRIN 1 showed the highest effect on the $\mathrm{Fv} / \mathrm{Fm}$ value as compared to the other principal parameters. This parameter explains $39 \%$ of total population variation and was used to develop a chlorophyll fluorescence model (Eq. (7)).

The predicted Fv/Fm values by the model showed a good agreement with measured ones. Standard error was $1.2 \%$ with minimum and maximum errors of 0.2 and $4.7 \%$, respectively (Fig. 8 ).

$$
\begin{aligned}
F v / F m_{\text {Estimated }} & =0.310031\left(F v / F m_{A T}\right)-0.010160\left(F v F m_{R Z T}\right) \\
& +0.257798\left(F v / F m_{C O 2}\right)+0.198054\left(F v / F m_{A C S}\right) \\
& -0.020619\left(F v / F m_{P P F}\right)-0.168842\left(F v / F m_{R H}\right) \\
& +0.384
\end{aligned}
$$

\section{Chlorophyll fluorescence response model with genetic algorithm}

Optimal growth of lettuce resulted from $22^{\circ} \mathrm{C}$ ambient temperature, $20^{\circ} \mathrm{C}$ solution temperature, $1,578 \mathrm{ppm}$ $\mathrm{CO}_{2}$ concentration, $1.3 \mathrm{~m} \cdot \mathrm{s}^{-1}$ air current speed, 216 $\mu \mathrm{mol} \cdot \mathrm{m}^{-2} \cdot \mathrm{s}^{-1} \mathrm{PPF}$, and $75 \%$ relative humidity. This result

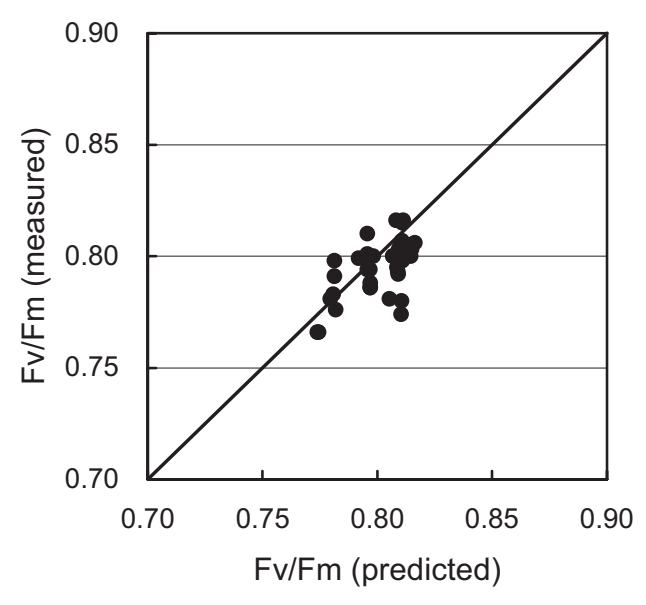

Fig. 8. Comparison of the measured and predicted Fv/Fm values

agreed with previous study results. Park and Lee ${ }^{19}$ reported that the highest photosynthetic rate of lettuce was observed at $200 \mu \mathrm{mol} \cdot \mathrm{m}^{-2} \cdot \mathrm{s}^{-1} \mathrm{PPF}$ and $1,000-2,000$ ppm $\mathrm{CO}_{2}$ concentration. The relationship between photosynthetic rate and relative humidity varied with cultivation environment conditions. The higher the relative humidity is, the faster the air current must be to improve photosynthetic rate. Air current speeds of $0.5-0.8 \mathrm{~m} \cdot \mathrm{s}^{-1}$ resulted in the greatest photosynthesis at $65 \%$ relative humidity, whereas the highest photosynthetic rate resulted from $1.0-1.5 \mathrm{~m} \cdot \mathrm{s}^{-1}$ air current speeds at $85 \%$ relative humidity ${ }^{31}$. At the range of $24-40^{\circ} \mathrm{C}$ ambient temperature, high $\mathrm{Fv} / \mathrm{Fm}$ values were observed when root zone temperature was maintained at $20^{\circ} \mathrm{C}$ as compared to the range from 23 to $40^{\circ} \mathrm{C}$. He et al.$^{8}$ reported better lettuce growth in the range of $15-25^{\circ} \mathrm{C}$ ambient temperature.

\section{Conclusion}

The relationships of chlorophyll fluorescence responses between each environmental factor (ambient 
temperature, $\mathrm{PPF}$, relative humidity, $\mathrm{CO}_{2}$ concentration, air current speed, and root zone temperature) and Fv/Fm values were analyzed. A chlorophyll fluorescence response model with the six environmental factors was developed using a principle component analysis and a simple genetic algorithm. The developed model predicted the observed Fv/Fm values. A simple genetic algorithm was incorporated into the chlorophyll fluorescence response model to predict an optimal environmental condition for lettuce growth. The optimal growth environment of lettuce was estimated to be $22^{\circ} \mathrm{C}$ ambient temperature, $20^{\circ} \mathrm{C}$ solution temperature, $1,578 \mathrm{ppm} \mathrm{CO}_{2}$ concentration, $1.3 \mathrm{~m} \cdot \mathrm{s}^{-1}$ air current speed, $216 \mu \mathrm{mol} \cdot \mathrm{m}^{-2} \cdot \mathrm{s}^{-1}$ $\mathrm{PPF}$, and $75 \%$ relative humidity.

The chlorophyll fluorescence can be a good method to measure the plant physiological responses to environmental change without damage to the plant. The Fv/Fm value can be also a good indicator of plant status to environmental stress and can be a useful parameter to optimize the environment for plant growth.

\section{References}

1. Babani, F., Lichtenthaler, H. K. \& Richter, P. (1998) Changes of chlorophyll fluorescence signatures during greening of etiolated barley seedlings as measured with the CCD-OMA fluorometer. J. Plant Physiol., 148, 471477.

2. Balachandran, S., Osmond, C. B. \& Daley, P. F. (1994) Diagnosis of the earliest strain-specific interactions between tobacco mosaic virus chloroplasts of tobacco leaves in vivo by means of chlorophyll fluorescence imaging. Plant Physiol., 104, 1059-1065.

3. Cantagallo, J. E. \& Hall, A. J. (2002) Seed number in sunflower as affected by light stress during the floret differentiation interval. Field Crops Res., 74, 173-181.

4. Couey, H. M. (1982) Chilling injury of crops of tropical and subtropical origin. HortScience, 17, 162-165.

5. Duysens, L. N. M. \& Sweers, H. E. (1963) Mechanism of the two photochemical reactions in algae as studied by means of fluorescence. In Studies on microalgae and photosynthetic bacteria, ed. Jpn. Soc. Plant Physiology, University of Tokyo Press, Tokyo, Japan, 353-372.

6. Goldberg, D. E., Korb, B. \& Deb, K. (1989) Messy genetic algorithms: motivation, analysis, and first results. Complex Sys., 3, 493-530.

7. Grantz, D. A. (1990) Plant response to atmospheric humidity. Plant Cell Environ., 13, 667-679.

8. He, J., Lee, S. K. \& Dodd, I. C. (2001) Limitations to photosynthesis of lettuce grown under tropical conditions: alleviation by root-zone cooling. J. Exp. Bot., 52(359), 1323-1330.

9. Holland, J. H. (1975) Adaptation in natural and artificial systems, 1st ed. The University of Michigan Press, Ann Arbor, MI, USA, pp.183.

10. Ioslovich, I. \& Seginer, I. (1998) Approximate seasonal optimization of the greenhouse environment for a multi- state-variable tomato model. Trans. ASAE, 41(4), 11391149.

11. Johnson, G. N. et al. (1993) The dissipation of excess excitation energy in British plant species. Plant Cell Environ., 16, 673-679.

12. Jolliffe, I. T. (2002) Principal component analysis. Springer, New York, USA, pp.502.

13. Jones, J. W. et al. (1991) A dynamic tomato growth and yield model (TOMGRO). Trans. ASAE, 34(2), 663-672.

14. Kim, H. K. et al. (1995) Effects of selected hydroponics and systems and nutrient solutions on the growth of leaf lettuce (Lactuca sativa L. var. crispa). J. Kor. Soc. Hort. Sci., 36(2), 151-157.

15. Kitaya, Y. et al. (2003) Effects of air current speed on gas exchange in plant leaves and plant canopies. Adv. Space Res., 31(1), 177-182.

16. Kooten, O. v. \& Snel, J. F. H. (1990) The use of chlorophyll fluorescence nomenclature in plant stress physiology. Photosynth. Res., 25, 147-150.

17. Lichtenthaler, H. K. (1988) Application of chlorophyll fluorescence in photosynthesis research, stress physiology, hydrobiology, and remote sensing. Kluwer Academic Publishers, Boston, USA, pp.384.

18. Lichtenthaler, H. K. (1996) Vegetation stress: an introduction to the stress concept in plants. J. Plant Physiol., 148, 4-14.

19. Park, M. H. \& Lee, Y. B. (1999) Effects of $\mathrm{CO}_{2}$ concentration, light intensity and nutrient level on the growth of leaf lettuce in a plant factory. J. Kor. Soc. Hort. Sci., 40(4), 431-435.

20. Rivero, R. M. et al. (2001) Resistance to cold and heat stress: accumulation of phenolic compounds in tomato and watermelon plants. Plant Sci., 160, 315-321.

21. Sánchez, F., Honrubia, M. \& Torres, P. (2001) Effects of $\mathrm{pH}$, water stress and temperature on in vitro cultures of ectomycorrhizal fungi from Mediterranean forests. Cryptogam. Mycol., 22(4), 243-258.

22. Schreiber, U. et al. (1998) Application of the PAM fluorometer in stress detection. In Applications of chlorophyll fluorescence in photosynthesis research, stress physiology, hydrobiology and remote sensing, ed. Lichtenthaler, H. K., Kluwer Academic Publishers, Boston, USA, 151155.

23. Shimizu, H. \& Yamazaki, M. (1992) Non-contact growth analysis using computer vision system. Acta Hort., 319, 641-646.

24. Sicora C., Máté, Z. \& Vass, I. (2003) The interaction of visible and UV-B light during photodamage and repair of photosystem II. Photosynth. Res., 75, 127-137.

25. Vass, I. (1996) Adverse effects of UV-B light on the structure and function of the photosynthetic apparatus. In Handbook of photosynthesis, ed. Pessarakli, M., Marcel Dekker, New York, USA, pp.96.

26. Walz (1999) Photosynthesis yield analyzer MINI-PAM. Heinz Walz GmbH, Effeltrich, Germany, pp.105.

27. Wang, C. Y. (1990) Chilling injury of horticultural crops. CRC Press, Boca Raton, Florida, pp.328.

28. Wilkerson, E. G. \& Gates, R. S. (2003) Controlled environment system for studying root zone temperature effects on cutting propagation. Appl. Eng. Agric., 19(4), 483-489. 
29. Willits, D. H. \& Peet, M. M. (1999) Using chlorophyll fluorescence to model leaf photosynthesis in greenhouse pepper and tomato. Acta Hort., 507, 311-317.

30. Willits, D. H. \& Peet, M. M. (2001) Measurement of chlorophyll fluorescence as a heat stress indicator in tomato: laboratory and greenhouse comparisons. J. Am.
Soc. Hort. Sci., 126(2), 188-194.

31. Yabuki, K. \& Miyagawa, H. (1970) Studies on the effect of wind speed upon the photosynthesis (2)-The relation between wind speed and photosynthesis. Nogyo Kisho (J. Agric. Meteorol.), 26(3), 137-141 [In Japanese with English summary]. 